\title{
Avoiding the Conflation of Moral and Intellectual Virtues
}

\author{
Alan T. Wilson ${ }^{1}$ \\ Accepted: 20 October 2017 / Published online: 4 November 2017 \\ (C) The Author(s) 2017. This article is an open access publication
}

\begin{abstract}
One of the most pressing challenges facing virtue theorists is the conflation problem. This problem concerns the difficulty of explaining the distinction between different types of virtue, such as the distinction between moral virtues and intellectual virtues. Julia Driver has argued that only an outcomes-based understanding of virtue can provide an adequate solution to the conflation problem. In this paper, I argue against Driver's outcomes-based account, and propose an alternative motivations-based solution. According to this proposal, intellectual virtues can be identified by the shared motivation for cognitive contact with reality, while moral virtues are identified by appeal to the characteristic motivations of kindness and justice. I defend the proposal by demonstrating that it produces plausible verdicts concerning the virtue status of candidate moral and intellectual virtues.
\end{abstract}

Keywords Intellectual virtue $\cdot$ Moral virtue $\cdot$ The conflation problem $\cdot$ Virtue ethics $\cdot$ Virtue epistemology

\section{Introduction}

The concept of virtue is important for many current debates within philosophy. The task of virtue theory - of giving an account of the virtues - is therefore an especially pressing one. One of the key challenges facing virtue theorists can be labelled the conflation problem, and concerns the attempt to distinguish between different types of virtue. In particular, I will focus on the conflation problem as it applies to the supposed distinction between moral and intellectual (or epistemic) virtues. Julia Driver (2003) has recently argued against existing attempts to explain this distinction, and suggested that only an outcomes-based understanding of virtue can provide an adequate solution to the conflation problem. My aim in this paper is to argue against Driver's outcomes-based account, and to propose an alternative motivationsbased solution.

Alan T. Wilson

atw.philosophy@gmail.com

1 Department of Philosophy, School of Arts, University of Bristol, Bristol BS8 1TH, UK 
I begin by briefly discussing the general problem and explaining why two initial proposals are unsuccessful (in Section II). I then argue against Driver's outcomes-based account (in Section III), before proposing my own motivations-based account (in Sections IV and V). According to this proposal, intellectual virtues can be identified by a shared underlying motivation (for cognitive contact with reality), while moral virtues can be identified by the presence of one of two different underlying motivations (kindness and justice). I defend this account by showing that it avoids the problems facing rival accounts, and by explaining how it leads to a plausible understanding of when (and why) candidate traits ought to be accepted as morally or intellectually virtuous (in Section VI).

\section{The Conflation Problem}

While there is much disagreement among virtue theorists regarding the nature of virtue, it is generally accepted that the basic concept of a virtue is of a quality that makes a person excellent in some way. ${ }^{1}$ Most virtue theorists also accept the distinction between moral virtues and intellectual virtues. ${ }^{2}$ The moral virtues are thought to include traits such as courage, justice, honesty, compassion, temperance, and kindness. Intellectual virtues are thought to include traits such as open-mindedness, intellectual rigour, intellectual humility, and inquisitiveness. The distinction between moral and intellectual virtues was accepted by Aristotle, and the influence of Aristotle perhaps partly explains why it is now generally assumed in the contemporary literature. ${ }^{3}$

The distinction is also important given the rise of both virtue epistemology and virtue ethics in recent times. If we want to assess the claim that knowledge consists of true belief achieved through intellectual virtue, then we will need to know which traits are the intellectual virtues. ${ }^{4}$ If we want to assess whether morally right actions are those that would be performed by a morally virtuous agent, then we need to know which traits are the moral virtues. ${ }^{5}$ The distinction between moral and intellectual virtues is therefore an important one for normative ethics and epistemology, as well as being generally accepted by contemporary virtue theorists. It is important that virtue theory has something to say about how this distinction should be understood.

Julia Driver (2003) argues that existing attempts to solve the conflation problem are unsuccessful. In the remainder of this section, I will briefly explain why two initial proposals can be rejected, before then moving on to discuss Driver's own outcomes-based account.

A first proposal for distinguishing between different types of virtue can be found in the work of Aristotle. Aristotle (1998, pp. 28-29 [1102 $\left.\left.{ }^{\mathrm{a}} 14-1103^{\mathrm{b}} 25\right]\right)$ suggests that moral and intellectual virtues are developed in different ways. Intellectual virtues are developed through teaching and instruction, while moral virtues are developed through a process of habituation.

\footnotetext{
${ }^{1}$ For a summary, see Battaly (2015, Ch. 1).

2 Plato did not acknowledge this distinction. See Moravcsik (1992, p. 300). There is also debate over whether Hume accepted the need for a distinction of this sort. See Driver (2003, pp. 368-370). Of course, the conflation problem only confronts those who accept the distinction.

${ }^{3}$ However, the specific examples of intellectual virtues that are discussed by Aristotle are notably different from those discussed in the contemporary debate. See Aristotle (1998, Bk. VI).

${ }^{4}$ See, for example, Zagzebski (1996), Greco (2010), and Prichard (2012).

${ }^{5}$ See, for example, Hursthouse (1999). (When setting out her account, Hursthouse refers to virtuous agents, rather than morally virtuous agents. However, the examples of virtues that Hursthouse uses makes it clear that she has the moral virtues in mind.)
} 
The moral novice needs to practice acting in virtuous ways, and through repetition and experience may come to develop genuine moral virtue. If this is correct, then it will be possible to distinguish different types of virtue by appealing to the different ways in which those virtues are developed. ${ }^{6}$

The problem with this proposal is that it struggles to accommodate those candidate intellectual virtues that are likely to require a process of habituation. ${ }^{7}$ Take, for example, the trait of inquisitiveness (understood as involving excellence in seeking out information and asking questions). An agent looking to develop this virtue might gain something from instruction, but ultimately she will need to engage in the process of asking questions, and of learning from experience the best way of doing so. Inquisitiveness plausibly owes its development to a process of habituation, and so the Aristotelian account appears to generate the wrong verdict. This difficulty deepens once we realise that inquisitiveness is far from the only possible counter-example. Traits such as open-mindedness and intellectual rigour, as well as the intellectual counterparts of familiar moral virtues (such as intellectual courage, charity, and humility), all plausibly require practice and habituation in order to be developed. This suggests that the process for developing intellectual virtues might, in general, be similar to the process for developing moral virtues. If this is correct, we will have reason to reject the Aristotelian approach to the conflation problem.

A second proposal for distinguishing moral and intellectual virtues focuses on the idea that morality is in some sense other-regarding. One way of developing this idea is to say that all moral virtues necessarily involve a concern for the well-being of others. Such a view is discussed by Driver (2003, pp. 371-372), who attributes it to Francis Hutcheson. In rejecting this approach, Driver (Ibid., p. 372) offers the following remarks:

There are... reasons for doubting that moral virtues have benevolence as a characteristic motivation: it is unclear that this needs to be the case for virtues like justice and honesty, for example.

The claim that all moral virtues involve benevolence, or a concern for the well-being of others, does not reflect the true complexity of moral life. There are candidate moral virtues that are not easily portrayed as involving such concern. Driver suggests that the traits of justice and honesty are counter-examples of this sort. While there is more to be said here, I agree with Driver that this initial proposal is overly-restrictive. Not all moral virtues necessarily involve a concern for the well-being of others, and so this initial proposal ought to be rejected. It will be important later on to demonstrate that my own proposal is not overly-restrictive in the same way.

Both of the initial proposals considered in this section face damaging counter-examples, and this should encourage us to consider alternatives. In the next section, I will focus on Driver's outcomes-based approach. As we shall we, Driver's approach offers an alternative way of developing the basic idea that morality is distinctively other-regarding.

\section{Rejecting Driver's Outcomes-Based Approach}

Outcomes-based approaches to virtue theory state that the defining feature of all virtues is the reliable production of good outcomes. Driver accepts this general account of virtue, and then

\footnotetext{
6 This approach is defended by James Wallace (1978, pp. 44-45).

${ }^{7}$ Zagzebski (1996, pp. 149-151) and Driver (2003, pp. 370-371) reject the Aristotelian account for this reason.
} 
refines it in order to account for the distinction between moral and intellectual virtues. Driver argues that different categories of virtue can be distinguished by thinking about the type of good outcomes that they produce, and about who those outcomes are typically produced for. Driver's (2003, p. 381) outcomes-based approach to the conflation problem is as follows:

Moral virtues produce benefits to others - in particular, they promote the well-being of others - while the intellectual virtues produce epistemic good for the agent.

This approach represents a different way of developing the basic idea that morality is distinctively other-regarding. However, Driver's account does not face the same problem as the proposal that all moral virtues involve a concern for the well-being of others. Even if traits like justice and honesty do not involve an active concern for other people, it might nevertheless be the case that those traits promote the well-being of other people (perhaps through promoting the good functioning of society as a whole). In this way, Driver's account looks to be an improvement on the benevolence-focused account discussed above.

However, Driver's account suffers from serious problems of its own. The most damaging problem for Driver is one that faces all outcomes-based approaches: the problem of luck. On Driver's account, a trait's status as a moral or intellectual virtue is determined by factors that are external to the trait itself. ${ }^{8}$ This has two problematic implications. First, if external circumstances are just right, then any trait can end up being classed as a moral or an intellectual virtue, regardless of how intuitively unappealing or banal that trait happens to be. Second, if the external circumstances that an agent finds herself in suddenly change, then the agent can switch from being morally virtuous to being intellectually virtuous (or even to being nonvirtuous) without actually undergoing any change in her own character. I will elaborate on these related issues in order to support the claim that we ought to reject Driver's account.

Consider first the problem that the outcomes-based approach allows for the virtue-status of intuitively unappealing traits. One example of this is actually provided by Driver (2001, p. 55), who asks us to imagine a society that has developed differently from normal human society and is populated by a race of "Mutors". The example is fleshed out in the following way:

It happens to be the case that for them, beating one's child severely when it is exactly 5.57 years old actually increases the life expectancy of the child by 50 percent. The child is upset by the beating, but this feeling goes away in time... So some Mutors have a special trait - they intensely desire to beat children who are exactly 5.57 years old. That it is good for the child is irrelevant to them.

A Mutor's intense desire to beat children will be classed as a moral virtue because being beaten happens to (systematically) lead to a longer life for the child. This result is generated even though the benefit to the child plays no role in motivating the Mutor to carry out the beating. Indeed, the same result would be generated even if the beating did not benefit the child, so long as it did (systematically) benefit some third-party to a greater extent than it harmed the child. In such cases, Driver's outcomes-based account makes it possible for the intense desire to beat children to be placed among the moral virtues.

This one example may be enough to cast doubt on the outcomes-based approach. Indeed, Driver (2004, p. 40) has admitted that "I myself am not comfortable at all with this case."

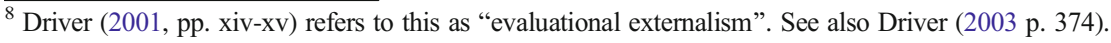


However, Driver also takes steps to lessen the force of the Mutor counter-example. She points out (Ibid. pp. 40-41) that the Mutor case is pure science-fiction, involving "alien beings" that are "wired differently and have evolved in different settings". Therefore, perhaps we ought not to trust our intuitions about this case. It is worth adding to the stock of counter-examples in order to demonstrate that Driver's approach generates problematic results.

Consider the possibility that the wealth of a nation is positively affected by the presence of citizens who are robustly focused on maximising their own profits. In order to become wealthy themselves, such individuals will employ other people and, if they are successful, this will increase the money that their government receives through taxation. The character traits involved will therefore have an overall positive effect (as long as the extra income is used to produce good outcomes). As Amartya Sen (1979, p. 468) has argued, the motivation of "profit maximisation" might, on the whole, produce a positive "utility sum". If so, the motivation for personal profit maximisation will be categorised as a virtue by the outcomes-based approach. ${ }^{9}$ Importantly, this verdict will be generated regardless of whether the agents in question are actually concerned about the good outcomes, and even if they are opposed to those outcomes. We therefore have another (non-science-fiction) example of an intuitively unappealing trait that has the potential to be wrongly categorised by Driver's account.

The outcomes-based approach not only produces problematic verdicts concerning traits that are intuitively unappealing. It also produces problematic verdicts concerning traits that are intuitively banal. Driver tells us that the moral virtues are those traits that have an overall positive impact on the well-being of others. This condition will be satisfied by traits that promote well-being in some minimal way, as long as they also have no negative impact. Consider a stable and persistent motivation to wave at passing trains. An agent with this motivation might systematically produce some minor good (the slight pleasure of passing passengers) without also leading to anything bad. On Driver's account, this will be enough to place the motivation to wave at trains among the moral virtues, even if the agent is in no way concerned about the slight positive impact on the well-being of others. ${ }^{10}$ These examples demonstrate that the outcomes-based approach has the potential to generate problematic verdicts concerning which traits are included as moral or intellectual virtues.

There is a second way in which the issue of luck causes problems for the outcomes-based approach. As well as leading to problematic verdicts concerning which traits are virtuous, the account also leads to an implausible picture of virtue development. According to Driver's account, it will be possible for an agent to switch from being virtuous to being non-virtuous (and vice-versa) even if there is no corresponding change in her own character.

For Driver, the status of a trait is determined by the outcomes generally produced by that trait in the agent's society. ${ }^{11}$ If an agent possesses a trait that generally leads to negative outcomes, then that agent will be categorised as vicious. In response to this, the agent might engage in the same process of habituation that Aristotle argued was necessary for the development of (moral) virtue. However, if Driver is correct, then an alternative route to virtue

\footnotetext{
${ }^{9}$ The type of virtue it is will depend on whether the extra resources are used to promote well-being or epistemic goods.

${ }^{10}$ We might worry that this motivation is too specific to count as a character trait, and so is not eligible for virtue status. One response to this worry would be to point out that the motivation is no more specific than other examples that Driver is happy to include as candidate moral or intellectual virtues (see Driver 2001, p. 57). A different response would be to change the example to a different type of banal trait, such as a very minor level of tidiness, or a general inoffensiveness.

${ }^{11}$ See, for example, Driver (2001, p.82), and also footnote 6 in Chapter 4 (printed on p. 120).
} 
would be to simply move to a different society. If the external circumstances change in the right way, then the agent can move from being vicious to being virtuous without having to alter any of her own character traits or behaviour. Similarly, the very same traits could make an agent either morally or intellectually virtuous, depending on the outcomes that those traits generally produce in the agent's society. Driver (2001, p. 82) argues that this is not "a form of pernicious relativism, since the criterion for virtue is universally the same." However, the relativism present in an approach that makes an agent's virtue-status dependent on her location does seem to be problematic.

These issues provide good reason to reject an outcomes-based approach to the conflation problem. However, Driver's strategy in defending that approach involves both a positive and a negative element. The positive element is to argue that the outcomes-based approach produces plausible results. I have argued that this is not the case. The negative element of Driver's strategy is to argue that rival proposals are unsuccessful. I will now challenge that claim by proposing and defending a motivations-based solution to the conflation problem.

\section{A Motivations-Based Approach to Identifying Intellectual Virtues}

In contrast to outcomes-based approaches, motivations-based approaches to virtue theory state that the defining feature of all virtues is the presence of a valuable motivational component. ${ }^{12}$ In this section, I will appeal to the work of Linda Zagzebski to defend a motivations-based approach to identifying intellectual virtues.

Zagzebski provides arguably the most influential contemporary account of intellectual virtues on which those traits necessarily involve a motivational component. Importantly, Zagzebski argues that all intellectual virtues share the same motivation - the motivation for "cognitive contact with reality" (Zagzebski 1996, pp. 131-132). Cognitive contact is then explained as being something of a placeholder term, meant to include epistemically valuable states such as true belief, knowledge, and understanding. ${ }^{13}$ For Zagzebski, all intellectual virtues involve this underlying motivation, although individual traits also involve their own proximal motivations. For example, the candidate intellectual virtue of inquisitiveness might involve a proximal motivation to ask questions, but this proximal motivation will be grounded in the underlying motivation to achieve cognitive contact with reality. Focusing on knowledge as a form of cognitive contact, Zagzebski (1996, p. 269) provides her own examples of the proximal motivations of candidate intellectual virtues:

the aim of open-mindedness is to be receptive to new ideas and arguments even when they conflict with one's own in order to ultimately get knowledge. The aim of intellectual thoroughness is to exhaustively investigate the evidence pertaining to a particular belief or set of questions in order to ultimately get knowledge. The aim of intellectual courage is to defend one's beliefs or a line of inquiry when one has good reason to be

\footnotetext{
${ }^{12}$ For a discussion of the theorists who can be understood as supporting either a broadly outcomes-based or a broadly motivations-based approach to the virtues, see Battaly (2015, Ch. 1).

${ }^{13}$ One question we might ask here is whether the agent needs to be motivated towards such epistemically valuable states de dicto or de re. On the Aristotelian assumption that a virtuous agent must know exactly what she is doing and why it is virtuous, we might prefer the de dicto reading. My own preference is for a de re reading, although I will remain neutral on this topic in this paper.
} 
confident that it is on the right track, and to fearlessly answer objections from others in order to ultimately get knowledge.

This aspect of Zagzebski's account has been highlighted by other theorists. Jason Baehr (2011, p. 133) explains that:

for Zagzebski, to possess a particular intellectual virtue $\mathrm{V}$ is to be motivated to bring about a certain end characteristic of $\mathrm{V}$ out of a deeper or more ultimate motivation to achieve knowledge or 'cognitive contact with reality.'

If Zagzebski is correct, then the conflation problem will have been at least partly solved. It will be possible to distinguish intellectual virtues by appealing to their shared underlying motivation for cognitive contact with reality.

Zagzebski's claim that all intellectual virtues involve being motivated towards cognitive contact with reality is rejected by Driver (2003, p. 376). Driver's reasoning is that:

some intellectual virtues may involve an at least limited failure to consider various aspects of reality - for example, focus and concentration may involve the capacity to exclude irrelevant (but true) facts.

This objection to Zagzebski is not successful. A quick response would be to deny that features such as focus and concentration are eligible for the status of intellectual virtue, due to the fact that they are not character traits. Driver (2001) does agree with Zagzebski that virtues are character traits. However, I do not want to rely on that fact here. Instead, it is possible to respond to Driver by focusing on the details of Zagzebski's account. For Zagzebski, "cognitive contact with reality" includes a collection of epistemically valuable states. Even if we accept that concentration can lead an agent to miss out on some (irrelevant) true beliefs, it may yet lead to other forms of cognitive contact, such as knowledge or understanding. If the agent is motivated to concentrate out of an underlying motivation to achieve some other form of cognitive contact, then Zagzebski's account has the potential to include concentration among the intellectual virtues.

Before moving on to discuss the moral virtues, I want to add some detail to Zagzebski's proposal. We should not accept that just any motivation for cognitive contact will be sufficient for intellectual virtue. The motivation in question must have certain features. Firstly, the motivation must be sufficiently persistent. The virtuously inquisitive agent is not one whose motivation to ask questions (and thereby achieve cognitive contact) is sporadic or fleeting. Similarly, the motivation must not be so weak that, even if persistent, it would never be strong enough to actually prompt the agent into action. That is, the virtuous motivation must be sufficiently strongly felt. Finally, the motivation involved in intellectual virtue must be sufficiently robust in the sense that it is not easily defeated by competing considerations. For example, if an agent's strong and persistent motivation to ask questions is always defeated by her competing aim of receiving bribes, then we will not say that her motivation is sufficient for virtuous inquisitiveness. When an agent's motivation for cognitive contact is sufficiently persistent, strongly felt, and robust, we can say that she possesses a deep motivation for cognitive contact. Only then will her motivation be sufficiently virtuous.

Solving the conflation problem requires providing an explanation for the distinction between moral and intellectual virtues. If we accept that all intellectual virtues share a deep 
underlying motivation for cognitive contact, then we will have taken an important step towards providing that explanation. I will now propose an analogous understanding of the moral virtues, and explain why the overall picture that emerges avoids the objections that trouble rival accounts.

\section{A Motivations-Based Approach to Identifying Moral Virtues}

An account of the moral virtues that directly mirrors Zagzebski's account of the intellectual virtues would need to identify an underlying motivation that is shared by all moral virtues. Zagzebski (1996, p. 166) denies that this is possible. One candidate underlying motivation was considered in Section II - the motivation to care about the well-being of others. This suggestion was deemed overly-restrictive as it cannot accommodate plausible moral virtues such as justice and honesty. My proposal differs from this initial account in two ways. Firstly, it proposes two different underlying motivations as relevant to the moral virtues. Secondly, it appeals to Zagzebski's distinction between underlying motivations and proximal motivations, and allows for a variety of different proximal motivations.

While all intellectual virtues involve the motivation for cognitive contact with reality, moral virtues can be distinguished by the presence of one of two underlying motivations. The first is the motivation to protect and promote well-being, as would be characteristic of the virtue of kindness. The second is the motivation to ensure fairness, as would be characteristic of the virtue of justice. Agents can possess a moral virtue either by having a general motivation for one of these ends - in which case they would possess the virtue of kindness or the virtue of justice - or by having a proximal motivation that is grounded in an underlying motivation for one of these ends. Specific candidate virtues will be discussed in more detail in the next section, but an example may be helpful here. The trait of intellectual rigour is an intellectual virtue because it involves a proximal motivation (to exhaustively examine the evidence) that is grounded in an underlying motivation for cognitive contact with reality. Analogously, the trait of generosity is a moral virtue when it involves a proximal motivation (to offer time or resources to others) that is grounded in an underlying motivation to protect and promote wellbeing.

An initial question here is why we ought to focus on the two underlying motivations that are proposed as fundamental by this account. That is, why should the moral virtues be identified by focusing specifically on the motivations of kindness (to protect and promote well-being) and justice (to ensure fair outcomes)? In answering this question, it is helpful to consider an analogous question that could be raised for Driver's outcomes-based approach. That analogous question is: why should the moral virtues be identified by focusing on the specific outcome of increased well-being for other people? In response, the outcomes-based theorist will reply that the moral value of this outcome is viewed as fundamental by the theory, and is not to be explained by reference to any further concept or criteria. The way to test this view is to check whether it results in plausible verdicts concerning the virtue status of candidate moral and intellectual virtues, and whether it avoids other potential problems. I argued in Section III that Driver's outcomes-based account is not successful in this regard. And the proposed motivations-based account ought to be evaluated via the same process. The best defence of the claim that the motivations of kindness and justice can be used to identify moral virtues is to show that this account results in plausible verdicts, and that it can avoid the 
problems that have been identified for rival solutions to the conflation problem. The remainder of this paper will focus on providing such a defence.

Identifying moral virtues by appeal to the characteristic motivations of kindness and justice avoids the problems that have been identified for rival accounts. For example, unlike the Aristotelian account, the motivations-based account makes no claims regarding how virtues are developed. The proposal is therefore not dependent upon there being a difference in the development of moral and intellectual virtues, and so is not hostage to future discoveries in this area.

The motivations-based account also avoids the problem of luck that is damaging for Driver's outcomes-based approach. For Driver, the virtue status of a trait is determined by factors that are external to the trait itself, and this leads to problematic results in cases where luck intervenes. On the motivations-based account, the important factor for distinguishing moral and intellectual virtues is the motivational component of those traits. Agents who are improperly motivated (such as the Mutor or the profit-maximiser) will not be classed as being thereby morally or intellectually virtuous, regardless of the external situation that they find themselves in. If an agent's fundamental motivation is neither to protect and promote wellbeing nor to ensure fair outcomes, then she does not possess moral virtue. This is true even if her actions happen to promote well-being, and even if actions of the sort that she performs reliably promote well-being in her society. If an agent is not deeply motivated in the correct way, then she is not morally virtuous. This feature of the account ensures that the motivationsbased approach avoids the problem of luck.

There is, however, one way in which agents will be subject to luck regardless of whether we accept an outcomes-based or a motivations-based approach. ${ }^{14}$ Both approaches are attempts to identify those aspects of character that are morally or intellectually virtuous. And it is true that the character we end up with is unlikely to be entirely of our own making. Our upbringing and life experiences will shape the character traits that we develop in ways that we can neither anticipate nor control. In this way, agents are subject to "constitutive luck" (Nagel 2013, p. 324) concerning which traits they ultimately possess. But this is different from saying that factors external to the traits themselves can determine whether those traits are virtues or vices, and it is different from saying that traits can switch between being morally or intellectually virtuous depending on what other people are doing in one's society. While both motivationsbased and outcomes-based approaches acknowledge the fact of constitutive luck, the motivations-based approach is immune from the more problematic forms of luck that have been shown to cause problems for Driver's outcomes-based account.

By avoiding any appeal to how virtues are developed, and by avoiding the problem of luck, the motivations-based account has important advantages over rival accounts. However, the most pressing potential worry for this proposal has not yet been addressed. The benevolencefocused account in Section II was rejected on the grounds that it is overly-restrictive. There are traits that are plausible moral virtues and that do not necessarily require a concern for other people. An obvious worry for the proposed motivations-based account is that it is overlyrestrictive in the same way. Won't there be plausible moral virtues that involve neither the motivation of kindness (to protect and promote well-being) nor the motivation of justice (to

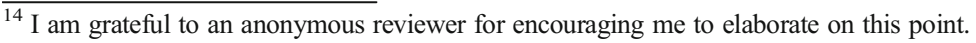


ensure fairness)? Theorists have discussed a wide variety of candidate virtues, and it would be surprising if they could all be associated with either kindness or justice. ${ }^{15}$ If the motivationsbased account cannot accommodate plausible moral virtues, then we will have reason to be sceptical of that account.

There is one basic way in which the proposed approach is less restrictive than the benevolence-focused account. The motivations-based account allows for a second type of morally relevant motivation - fairness-based considerations are added to well-being-based considerations. But this addition alone is unlikely to satisfy those who are worried about an overly-restrictive account of the moral virtues. Instead, this objection can best be addressed by appealing to the distinction between underlying and proximal motivations that is vital to Zagzebski's account of intellectual virtues. By allowing for a wide range of proximal motivations, it becomes possible for the motivations-based account to accommodate standardly accepted moral virtues, in addition to kindness and justice. In the next section, I will provide further support for the motivations-based account by discussing specific candidate virtues and demonstrating that they can be accommodated by the proposal. In the process of doing so, I will explain how the approach results in a plausible understanding of when (and why) candidate traits ought to be accepted as either morally or intellectually virtuous.

\section{Testing the Proposed Distinction}

A successful solution to the conflation problem will produce plausible results concerning which traits are moral or intellectual virtues. This requires accommodating standardly accepted candidate traits, or else being able to explain why those traits ought to be excluded. While it will obviously not be possible to discuss every candidate moral and intellectual virtue in this paper, the general strategy for extending the list of moral virtues beyond kindness and justice can be demonstrated by considering just a few examples. In this section, I will briefly discuss the traits of honesty, modesty, and compassion in an attempt to show that the motivationsbased account is not overly-restrictive.

\subsection{Honesty}

Being honest requires more than simply never saying anything false. We can imagine a Robinson Crusoe figure whose utter isolation means that he never speaks, and so never says anything false. Such a figure would not thereby deserve to be considered honest. ${ }^{16}$ Similarly, it is also not sufficient for honesty that an agent regularly (and exclusively) utters truths. We can imagine an agent who wanders around reading aloud every piece of text that she comes across, and who never happens to stumble upon a falsehood. Such an agent is not thereby honest. What is lacking in these examples is the presence of a relevant motivation. Honest individuals

\footnotetext{
${ }^{15}$ For example, the index to Robert Adams' A Theory of Virtue (Adams 2006) references over sixty virtue terms. David Hume famously mentions over thirty candidate virtues in a single passage. See Hume (2011, Section 6, Part 1).

${ }^{16}$ A Robison Crusoe example is used by Driver (2001, Ch. 2) to reject a similarly basic account of modesty.
} 
do not just happen to say things that are true, they are actively and deeply motivated to avoid deception. $^{17}$

It is possible for this characteristically honest motivation to be grounded in any number of additional, underlying motivations. For example, if an agent believes that any deception is likely to be uncovered and severely punished, then her motivation to avoid deception may be grounded in an underlying motivation to avoid punishment. For present purposes, we can consider the possibility of a motivation to avoid deception that is grounded in the motivation to protect and promote well-being. An agent who is honest in this way will be motivated to avoid deception in cases where the deception would be cruel, or where it would harm the interests of someone else. Such an agent can be referred to as possessing honesty-as-kindness, and it will be possible for this form of honesty to be included as a moral virtue on the motivations-based account.

A further possibility is for the motivation to avoid deception to be grounded in an underlying motivation to ensure fairness. An agent who is motivated in this way will be particularly opposed to deception in cases where it would be unfair to withhold information from another, or where she feels that she "owes it" to someone to tell the truth. This form of honesty involves the motivation of justice, and can be referred to as honesty-as-justice. On the proposed motivations-based solution to the conflation problem, both honesty-as-kindness and honesty-as-justice will be included among the moral virtues.

However, other forms of honesty will not be included as morally virtuous. And this looks to be the correct result. Imagine an agent who delights in revealing hurtful truths, and who decides that "honesty is the best policy" because this increases her chances of doing so. Straightforward accounts on which honesty is always a virtue will be forced to say either that this agent is not in fact honest, or that she possesses a morally virtuous trait. The proposed account allows for a different and more nuanced response. Only those forms of honesty that share in the underlying motivations of kindness or justice are included as morally virtuous. An agent whose avoidance of deception is grounded in a desire to reveal hurtful truths may well be honest, but she will not thereby be morally virtuous. Honesty that is grounded in negative (or indifferent) motivations ought not to be considered virtuous, even if we have no reason to deny that the possessors of such traits are indeed honest. The motivations-based account provides an understanding of honesty that allows us to endorse this intuitively appealing position.

\subsection{Modesty}

Additional candidate moral virtues can be accommodated in the same way. For a further example, consider the trait of modesty. Modesty has proven to be surprisingly controversial within virtue theory in recent times, and it would require too much of a detour from the central theme of this paper to engage fully with the complexities of that debate. ${ }^{18}$ Instead, the task here is to identify a plausible characteristic motivation for modesty, and to argue that the trait is only morally virtuous when that characteristic motivation is grounded in the underlying motivations of either kindness or justice.

\footnotetext{
${ }^{17}$ Honesty has been relatively overlooked in the recent drive to account for the nature of specific virtuous traits. My focus here is on how honesty can be accommodated by a motivations-based solution to the conflation problem. I develop a more detailed account of the nature of honesty in my "Honesty as a Virtue" (manuscript).

${ }^{18}$ For a sense of the debate on modesty, see Driver (2001, Ch. 2); Ridge (2000); Brennan (2007); and McMullin (2010). I provide a more detailed defence of an account of modesty in Wilson (2016).
} 
A plausible characteristic motivation for the trait of modesty is the motivation to de-emphasise one's positive attributes or accomplishments. An agent may possess this motivation out of an underlying motivation to be well-liked, or to lull potential opponents into a false sense of security. In such cases, the agent's modesty ought not to be considered morally virtuous. However, it is also possible to be motivated to de-emphasise your accomplishments out a further motivation to protect the well-being of those around you. For example, an academic might refrain from repeatedly mentioning her recent publication success when in the presence of less fortunate colleagues. Such a form of modesty can be referred to as modesty-as-kindness, and is plausibly morally virtuous. Similarly, an agent may be motivated to de-emphasise her accomplishments out of a sense of fairness. For example, a footballer might downplay the importance of her winning goal out of a concern that the media will fail to give due consideration to the contribution of her teammates. When an agent's modesty is grounded in this way, we can say that she possesses modesty-as-justice. The motivations-based approach to the conflation problem will include modesty as a moral virtue when it is possessed as either modesty-as-kindness or modesty-as-justice.

\subsection{Compassion}

The discussions of honesty and modesty highlight a general strategy for responding to the worry that the motivations-based account is overly-restrictive. Additional candidate moral virtues can be accommodated by uncovering the characteristic motivation for each trait and then arguing that forms of the trait are morally virtuous only when grounded in either kindness or justice. It will be useful to discuss one final example of a specific virtue in order to demonstrate an alternative way in which additional traits can be included.

In the intellectual realm, the characteristic motivation for cognitive contact with reality incorporates a range of epistemically valuable states that are likely to include true belief, knowledge, and understanding. Importantly, an agent can possess an intellectual virtue without being motivated towards all of these epistemically valuable states. Some virtues may be more concerned with understanding, for example, and less with amassing true beliefs. ${ }^{19}$ While some intellectual virtues involve the possession of a characteristic proximal motivation, other intellectual virtues might involve a direct motivation towards a restricted set of the epistemically valuable states.

In a similar way, it will be possible for a moral virtue to involve a direct motivation towards only one aspect of protecting and promoting well-being, or ensuring fairness. One example of this is the trait of compassion. A compassionate agent will be deeply motivated to alleviate the suffering of others. This trait ought to be included as a moral virtue, but this need not be because the motivation to alleviate suffering is grounded in an additional motivation to promote well-being or to ensure fairness. Instead, the alleviation of suffering just is one way of promoting well-being. Compassion can therefore be accepted as directly involving (a restricted form of) the motivation of kindness, and this allows it to be included as a moral virtue on the proposed approach.

\subsection{Further Implications}

The worry that the motivations-based account will be overly-restrictive is alleviated by the fact that it can accommodate candidate virtues as diverse as honesty, modesty, and compassion (as well as kindness and justice). While a comprehensive defence of the account would require a

${ }^{19}$ This is acknowledged by Zagzebski (1996, p. 167). 
more detailed discussion of many more virtuous traits, the above sections provide a blueprint for how that discussion would proceed..$^{20}$ The successful inclusion of honesty, modesty, and compassion demonstrates the promise of the account, and provides reason to think that it can avoid the charge of being overly-restrictive. If so, the motivations-based account will have successfully responded to the objections that have been raised for rival accounts. Before concluding, I want to briefly highlight some further implications of the view.

Intellectual virtues and moral virtues are distinguished by their underlying motivations. One interesting implication of this view is that it will be possible for different forms of the same trait to differ in terms of their virtue status. That is, one form of a given trait (such as honesty) might be morally virtuous, while another form of the trait is intellectually virtuous, or even nonvirtuous. Two final examples will help to demonstrate the plausibility of this implication.

One widely accepted intellectual virtue is the trait of inquisitiveness, which involves a characteristic motivation to ask questions. This characteristic motivation will often be grounded in an underlying motivation to attain knowledge, and inquisitiveness can rightly be categorised as an intellectual virtue in such cases. However, inquisitiveness can also share in the motivations of kindness and justice. An agent could be motivated to ask questions out of an underlying motivation to protect well-being. We might hope that medical practitioners and social workers will possess inquisitiveness in this form. Similarly, an agent could be motivated to ask questions out of a deeper motivation to ensure fairness. This form of inquisitiveness will hopefully be possessed by judges and police officers. These forms of inquisitiveness - inquisitiveness-askindness and inquisitiveness-as-justice - ought to be included among the moral virtues. Furthermore, some agents may have a motivation to ask questions that is grounded in an underlying motivation to embarrass others, or to make themselves look good. These forms of inquisitiveness ought not to be classed as either morally or intellectually virtuous.

The possibility that different forms of the same trait will differ in terms of their virtue status also applies to standardly accepted moral virtues. The earlier discussion explained how honesty-as-kindness and honesty-as-justice will be included as moral virtues on the proposed account, while honesty based on cruel motivations will be rejected as non-virtuous. It is also possible to possess honesty in a way that is intellectually virtuous. An agent may possess a deep motivation to avoid deception that is grounded in an underlying motivation for truth. This form of honesty will be identified as an intellectual virtue.

That the trait of honesty divides up in this way explains the difficulty experienced by Driver when trying to deal with that trait. Driver is unsure where to place honesty among the virtues, and this leads her to suggest that: "There is also the possibility that things just are fuzzy, and that is why some virtues are difficult to classify" (Driver 2003, p. 381). The motivations-based account reveals the cause of this apparent fuzziness. If we focus only on honesty's characteristic proximal motivation to avoid deception, then it is difficult to classify the trait as either morally or intellectually virtuous. This difficulty is explained once we focus on the underlying motivations involved in different forms of honesty. This focus reveals to us that different forms of honesty differ in terms of their virtue status, and this is why it is difficult to classify honesty in general. By providing this explanation, as well as providing a plausible account of when honesty ought to be considered virtuous, the motivations-based account recommends itself for acceptance.

\footnotetext{
${ }^{20}$ Some may worry that the trait of courage will be difficult to incorporate, because they believe that courage does not involve any characteristic motivation. See, for example, Roberts and Wood (2007, pp. 79-80). One option here is to follow Zagzebski's discussion (1996, p. 269) on which courage involves the characteristic motivation to face down challenges and defend things that are of value. A more radical option would be to argue that courage is not a virtue, but merely an enabler for virtue. I will not pursue that more radical option here.
} 
The aim of this section has been to demonstrate that the motivations-based account can accommodate a variety of different candidate virtues, and so is able to respond to the charge of being overly-restrictive. If successful, this would mean that the account avoids all of the objections that have been discussed for rival accounts, while also generating plausible verdicts concerning when (and why) traits ought to be accepted as morally or intellectually virtuous. This provides us with good reason to accept the motivations-based account as offering a promising solution to the conflation problem.

\section{Conclusion}

The conflation problem faces all virtue theorists who accept a distinction between moral and intellectual virtues. In this paper, I have argued against an outcomes-based approach to the conflation problem and proposed an alternative motivations-based solution. This solution avoids the problems facing rival accounts, while also generating plausible verdicts concerning when (and why) certain traits can be considered morally or intellectually virtuous. Given this, there is good reason to accept a motivations-based approach to the conflation problem. ${ }^{21}$

Open Access This article is distributed under the terms of the Creative Commons Attribution 4.0 International License (http://creativecommons.org/licenses/by/4.0/), which permits unrestricted use, distribution, and reproduction in any medium, provided you give appropriate credit to the original author(s) and the source, provide a link to the Creative Commons license, and indicate if changes were made.

\section{References}

Adams RM (2006) A theory of virtue. Clarendon Press, Oxford

Aristotle (trans. D Ross) (1998) The nicomachean ethics. Oxford University Press, Oxford

Baehr J (2011) The inquiring mind. Oxford University Press, Oxford

Battaly H (2015) Virtue. Polity Press, Malden

Brennan J (2007) Modesty without illusion. Philos Phenomenol Res 75:111-128

Driver J (2001) Uneasy virtue. Cambridge University Press, Cambridge

Driver J (2003) The conflation of moral and epistemic virtue. Metaphilosophy 13:367-383

Driver J (2004) Response to my critics. Utilitas 16:33-41

Greco J (2010) Achieving knowledge. Cambridge University Press, Cambridge

Hume D (2011) An enquiry concerning the principle of morals. In: Hume: the essential philosophical works.

Wordsworth Editions Limited, Ware, Hertfordshire, pp 707-831

Hursthouse R (1999) On virtue ethics. Oxford University Press, Oxford

McMullin I (2010) A modest proposal: accounting for the virtuousness of modesty. Philos Q 60:787-807

Moravcsik J (1992) Plato and platonism. Blackwell Publishing, Cambridge

Nagel T (2013) Moral luck. In: Shafer-Landau R (ed) Ethical theory: an anthology, $2^{\text {nd }}$ edn. Wiley-Blackwell, Malden, pp 322-329

Prichard D (2012) Anti-luck virtue epistemology. J Philos 109:247-279

Ridge M (2000) Modesty as a virtue. Am Philos Q 37:269-383

Roberts R, Wood J (2007) Intellectual virtues. Oxford University Press, Oxford

Sen A (1979) Utilitarianism and welfarism. J Philos 76:463-489

Wallace J (1978) Virtues and vices. Cornell University Press, Ithaca

Wilson AT (2016) Modesty as kindness. Ratio 29:73-88

Zagzebski LT (1996) Virtues of the mind. Cambridge University Press, Cambridge

\footnotetext{
${ }^{21}$ I am grateful to Matthew Chrisman, Allan Hazlett, Elinor Mason, Christian Miller, Lani Watson, and the anonymous reviewers for helpful written comments on earlier drafts of this paper. I am also grateful to members of the Work in Progress groups at the University of Edinburgh and Wake Forest University, and to participants at the Aretai Centre conference in Genoa in 2016 for helpful discussion. Work on this article was supported by a grant from the Templeton Religion Trust. The opinions expressed here are those of the author, and do not necessarily reflect the views of the Templeton Religion Trust.
} 